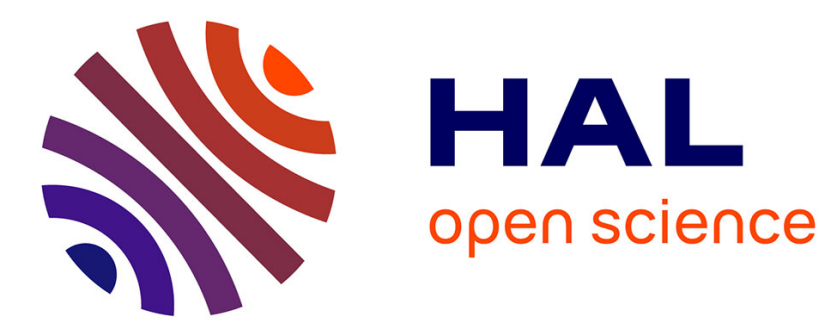

\title{
Analysis of multiple fatigue cracks-part I: Theory
}

Marie-Christine Baietto, B. Villechaise

\section{To cite this version:}

Marie-Christine Baietto, B. Villechaise. Analysis of multiple fatigue cracks-part I: Theory. Journal of Tribology, 1992, 114 (3), pp.455-461. 10.1115/1.2920905 . hal-01951916

\section{HAL Id: hal-01951916 https://hal.science/hal-01951916}

Submitted on 6 Jul 2021

HAL is a multi-disciplinary open access archive for the deposit and dissemination of scientific research documents, whether they are published or not. The documents may come from teaching and research institutions in France or abroad, or from public or private research centers.
L'archive ouverte pluridisciplinaire HAL, est destinée au dépôt et à la diffusion de documents scientifiques de niveau recherche, publiés ou non, émanant des établissements d'enseignement et de recherche français ou étrangers, des laboratoires publics ou privés. 


\section{Analysis of Multiple Fatigue Cracks-Part I: Theory}

This paper analyzes the effects of multiple cracks situated in the contact zone vicinity of an elastic isotropic component, modeled as a half-plane. Friction between the crack faces is taken into account using Coulomb's law. Straight arbitrarily oriented cracks are considered. Any contact condition can be modeled between the crack faces as well as any loading condition over the half-plane surface, including complete loading cycles. The method has been tested for up to 5 cracks and shows no limitation in crack number. Further, the method is general as no prior assumptions concerning the state of the crack, i.e., the slip-stick-open configurations along the crack are required. The stress intensity factors (SIFs) calculated for two crack configuration are compared with those obtained for single cracks.

\author{
M. C. Dubourg \\ Laboratoire de Mécanique des Contacts \\ (CNRS URA 856), \\ Institut National des Sciences Appliquées \\ de Lyon, \\ 69621 Villeurbanne Cédex, France \\ B. Villechaise \\ Laboratoire de Mécanique des Solides \\ (CNRS URA 861), \\ Université de Poitiers, \\ 86022 Poitiers Cédex, France
}

\section{Introduction}

Numerical methods are generally used for practical cracking problems involving finite geometries and complex loading. High accuracy implies important computer time. In the case of cracking initiated in localized contact problems, semianalytical methods offer an interesting alternative. Therefore considerable research effort has been devoted to extend the application field of analytical solutions, which was limited to only a few idealized cases. Straight or kinked cracks situated in an isotropic elastic material or at the interface of a two phase material were analyzed. Thus Comninou $(1977,1978)$ solved the interface crack problem, taking into account friction between the crack faces. Comninou and Schmueser (1980), Comninou et al. (1983), Chang et al. (1984), Kim et al. (1990) considered various loading conditions, including moving loads. Later, Hills and Comninou (1985a, b) considered a crack perpendicular to the surface. This work was extended to various loading cases (Sheppard et al., 1986). Arbitrarily oriented (Nowell and Hills, 1987) Keer and Bryant, 1983), or kinked cracks (Miller and Stock, 1989) were also considered. In the three last cases the analysis was devoted to completely open cracks. Therefore, due to the crack modeling complexity, and to the difficulties of solving the contact problem between the crack lips, the analyses mentioned above were limited either to predefinite states of the crack for given ranges of loading conditions and crack data, or to open cracks. Bower (1988) remove this limitation for the case of an arbitrarily oriented crack situated in an isotropic medium. Note that the case of multiple cracks has received relatively little attention so far. Keer et al. (1982) have analyzed the situation created by having two open cracks.

The purpose of the present analysis is to study multiple crack interactions to provide an additional tool to study the con- ditions under which failure occurs: mutual interactions between cracks may strongly modify the stress field near the tips of the cracks and thus the stress intensity factors (SIFs). A general model was constructed to perform this analysis under any loading conditions (including complete cycles) and crack geometries in an isotropic elastic medium. It includes a new formulation for the crack model and also for the interfacial contact problem solution. Satisfactory comparisons (Dubourg, 1989) with the literature (Hills and Comninou, 1985a, b; Bower, 1988) and with experimental results (Dubourg et al., 1988) were performed for a single crack.

In this paper the modified crack modeling in terms of the dislocation theory is first described. Then the contact problem solution is presented in the next section. An application serves as illustration.

\section{Modeling}

As mentioned above, a semianalytical solution is obtained for a normal and tangential distribution of tractions over the surface of a multiply cracked half-plane. The solution $\left(\sigma^{T}\right)$ is obtained by superposition of the solutions corresponding to the homogeneous half-plane response to the load (I) and to the crack response (II), i.e., stresses generated by relative displacements along the cracks.

Stress $\left(\sigma^{\mathrm{MC}}\right)$ and displacement fields corresponding to (I) have been determined by summing the elementary stress and displacement components obtained from appropriate Airy stress functions associated with concentrated normal and tangential loads.

Relative displacement zones within the crack are modeled as continuous distributions of edge dislocations of Burgers vectors $b_{x}$ and $b_{y}$. Elastic fields $\left(\sigma^{F}\right)$ corresponding to (II) are obtained from the literature (Dundurs and Mura, 1964). This technique, already used in the models mentioned in $\S \mathrm{I}$, is modified and adapted to the contact problem solution.

Load cycles are described with an incremental description which takes into account the load history, as hysteresis is in- 


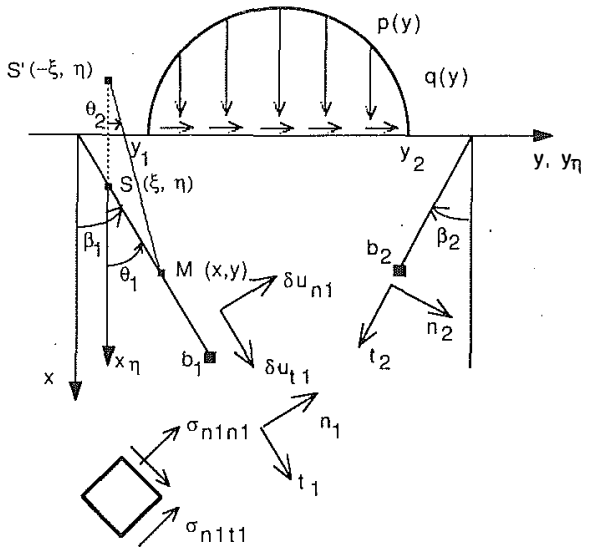

Fig. 1 Notations used in case of two cracks

troduced by the frictional contact between the crack lips. The load is then applied in small steps. Thus, for incremental variations of the loading zone position $\Delta_{y}$, of the loading components $\Delta p$ and $\Delta q$, the boundary conditions for the overall problem are the following (Fig. 1):

Surface boundary conditions step $i+1$

$$
\begin{array}{cc}
y 1+\Delta y<y<y 2+\Delta y & y>y 2+\Delta y, y<y 1+\Delta y \\
\text { (1) } \sigma_{x x}^{T}(0, y)=-(p(y)+\Delta p) & \text { (3) } \sigma_{x x}^{T}(0, y)=0 \\
\text { (2) } \sigma_{x y}^{T}(0, y)=-(q(y)+\Delta q) & \text { (4) } \sigma_{x y}^{T}(0, y)=0
\end{array}
$$

Note that displacement boundary conditions are formulated in terms of displacement increments:

A "stick condition" means that the tangential displacement increment $\Delta u_{t}$ is nil

$$
\delta u_{t}^{i+1}=\delta u_{t}^{i}+\Delta u_{t}^{i+1}, \Delta u_{t}^{i+1}=0
$$

A "contact condition" means that a zone that was previously open is now closed.

$$
\delta u_{n}^{i+1}=\delta u_{n}^{i}+\Delta u_{n}^{i+1}, \Delta u_{n}^{i+1}=-\delta u_{n}^{i}
$$

(case II). In both cases, artificial singularities are imposed that guarantee the correct behavior of the stress field along the crack: square root singular at crack tips, bounded elsewhere. The strength of these singularities may then be driven numerically to zero as in case of a stick zone at the crack tip. Consistency equations come from corresponding boundary conditions $\left(\delta u_{n}=0, \delta u_{t}=0\right)$.

The multiple crack model is presented using a two crack configuration (Fig. 1). Stresses and relative displacements, labeled versus the crack number $i$, are expressed in the reference axes $\left(n_{i}, t_{i}\right)$ related to the corresponding crack. Thus $\Gamma 1$ and $\Gamma 2$ are the potential displacement zones. The dislocation distributions are $\left(b_{1 x}, b_{1 y}\right)$ and $\left(b_{2 x}, b_{2 y}\right) ; M 1$ and $M 2$ refer to points which belong to the corresponding crack.

$$
\begin{aligned}
\sigma_{i j}^{F}(x, y)= & \frac{2 \mu}{\pi(k+1)}\left[\int _ { \Gamma 1 } \left[b_{1 x}(\xi) K_{i j}^{x}\left(x, y_{\eta}, \xi\right)\right.\right. \\
& +b_{1 y}(\xi) K_{i j}^{y}\left(x, y_{\eta}, \xi\right) d \xi+\int_{\Gamma 2}\left[b_{2 x}(\xi) K_{i j}^{x}\left(x, y_{\eta}, \xi\right)\right. \\
& \left.\left.+b_{2 y}(\xi) K_{i j}^{y}\left(x, y_{\eta}, \xi\right)\right] d \xi\right]
\end{aligned}
$$

$i, j=n_{1}, t_{1}$ for a point $M 1$ or $n_{2}, t_{2}$ for a point $M 2$.

$$
\begin{aligned}
& \delta u_{n}(x, y)=\delta u_{y} \cos \beta-\delta u_{x} \sin \beta \\
& \delta u_{t}(x, y)=\delta u_{x} \cos \beta+\delta u_{y} \sin \beta
\end{aligned}
$$

with,

$$
\begin{array}{r}
\delta u_{x}(x, y)=\frac{1}{2 \pi(k+1)} \int_{\Gamma}\left[b_{x}(\xi) D_{x}^{x}\left(x, y_{\eta}, \theta, \xi\right)\right. \\
\left.+b_{y}(\xi) D_{x}^{y}\left(x, y_{\eta}, \theta, \xi\right)\right] d \xi \\
\delta u_{y}(x, y)=\frac{1}{2 \pi(k+1)} \int_{\Gamma}\left[b_{x}(\xi) D_{y}^{x}\left(x, y_{\eta}, \theta, \xi\right)\right. \\
\left.+b_{y}(\xi) D_{y}^{y}\left(x, y_{\eta}, \theta, \xi\right)\right] d \xi
\end{array}
$$

$\mu$ is the shear modulus, $k=3-4 \nu$ for plane strain, or $(3-\nu) /$ $(1+\nu)$ for plane stress, $\nu$ the Poisson's ratio, $K_{i j}^{x}, K_{i j}^{y}$ the stress kernels and $D_{i}^{j}$ the displacement kernels are defined in the
Open zone

(5) $\sigma_{n n}^{T}(M)=0$

(6) $\sigma_{n t}^{T}(M)=0$

(7) $\delta u_{n}^{i+1}(M)>0$

Interfacial boundary conditions for $M(x, y)$ step $i+1$
(8) $\delta u_{n}^{i+1}(M)=0$
Contact zone
Contact stick zone
(10) $\delta u_{t}^{\prime+1}(m)=0$
(11) $\left|\sigma_{n t}^{T}(M)\right|<f\left|\sigma_{n n}^{T}(M)\right|$
(9) $\sigma_{n n}^{7}(M) \leq 0$
Contact slip zone
(12) $\left.\left|\sigma_{n t}^{T}(M)\right|=f \mid \sigma_{n n}^{T} M\right) \mid$
(13) $\delta u_{t}^{i+1}(M) \cdot \sigma_{n t}^{T}(M) \leq \phi \leq 0$

II.1 Crack Modeling. As mentioned above, displacement zones along the crack are modeled with continuous dislocation distributions. In the models cited in $\S \mathrm{I}$, the dislocation behavior on each displacement zone corresponds to the stress behavior, i.e., regular of square root singular. Thus the number of displacement zones, their length, their relative position along the crack have to be known and thus assumptions are formulated on the state of the crack.

One of the main conditions to ensure the construction of a general model is to get a single stress and displacement formulation for the whole crack, independent from the contact conditions. To reach this goal, the following steps were followed:

The crack is considered as a whole potential displacement zone $(\Gamma)$ that may contain several different zones of slip, stick, and opening; unique dislocations distributions $b_{x}$ and $b_{y}$ are considered.

The dislocation density depends only on the crack geometry, whether it is a subsurface (case I) or a surface breaking crack
Appendix. The displacement field is made unique by imposing $\beta_{i}<\beta<\beta_{i}+2 \pi, \beta_{i}$ being the crack angle (Fig. 1).

It may be noted that the stress field at a point $M$ belonging to a crack is influenced by the presence of other cracks. But as the stress kernels (cf Appendix) decay as $1 / r$, where $r$ is the distance from the point $M$ to the point where the dislocation is, the influence is mostly concerned with the closest points. The relative displacement expressions are the same as in the case of a single crack as displacements generated by the presence of crack 2 induce no relative displacements between the faces of crack 1 and vice-versa.

The method presented has been developed for a two crack situation. For multiple $(m)$ cracks, it is necessary to include supplementary terms in Eq. (14) which then reads:

$$
\begin{aligned}
\sigma_{i j}^{F}(x, y)=\frac{2 \mu}{\pi(k+1)} \sum_{l=1}^{m} \int_{\Gamma l}\left[b_{1 x}(\xi) K_{i j}^{x}\left(x, y_{\eta}, \xi\right)\right. \\
\left.+b_{1 y}(\xi) K_{i j}^{y}\left(x, y_{\eta}, \xi\right)\right] d \xi
\end{aligned}
$$


The numerical solutions employed to solve these singular integrals are those developed by Erdogan et al. (1973). First each interval $[a, b]$ corresponding to a crack ( $a=0$ for a surface breaking crack) is normalized by a change of variables:

with

$$
x / L=\epsilon s+\gamma \quad \xi / L=\epsilon r+\gamma
$$

$$
\epsilon \quad=(b-a) / 2 L \quad \gamma=(b+a) / 2 L
$$

Integrable singularities are incorporating in $b_{x}(\xi)$ and $b_{y}(\xi)$ by letting:

$$
\begin{aligned}
& b_{x}(\xi)=\phi(\xi)(1-\xi)^{\alpha}(1+\xi)^{\beta} \\
& b_{y}(\xi)=\psi(\xi)(1-\xi)^{\alpha}(1+\xi)^{\beta}
\end{aligned}
$$

where in case I $\alpha=-\beta=-1 / 2$ and in case II $\alpha=\beta=-1 / 2$.

Integrations points $r_{i}$ and collocation points $s_{k}$ are chosen (Erdogan and al., 1973) dition are forced in the open zone. This goes on until a stable distribution of the potential contact area is reached.

Condition (7) is then verified for all points belonging to the potential open zone. Points which do not verify this condition are introduced in the contact zone; both procedures must be repeated if the open zone distribution is modified.

Convergence is reached when both tests are satisfied. The tangential problem is then solved, with $\sigma_{m}$ given. Equations (10) or (12) are used if the point is in a stick or in a slip zone. Again, two iterative sequences are used.

Condition (11) is tested for all points in the stick zone. Points which do not satisfy this condition are set in the slip zone. This goes on again until a stable situation is reached.

Condition (13) is verified for all points belonging to the slip zone. Points which do not satisfy this condition are introduced
Case I

(22) $r_{j}=\cos ((2 i-1) \pi / 2 n) i=1, \ldots n$

$$
\text { (23) } s_{k}=\cos (\pi k / n) \quad k=1, \ldots n-1
$$

(24) $r_{i}=\cos ((2 i-1) \pi /(2 n+1)) i=1, . n$ (25) $s_{k}=\cos (2 k \pi /(2 n+1)) \quad k=1, . n$
In case I, further conditions are imposed to ensure the uniqueness of the displacement field: $\delta u_{n}=0, \delta u_{t}=0$ at the upper tip of the crack $(k=n-1)$.

II.2 Contact Problem Solution. The distributions of normal and tangential tractions that satisfy the boundary conditions, involving equalities and inequalities, at the crack interface are solved for. A systematic approach is proposed to avoid assumptions that limit the application field of previous models (cf $\S \mathrm{I})$. Futhermore, it is impossible to anticipate the states of the cracks for multiple cracks due to the complex sequences of stick, slip and open zones that may result. Thus the problem is solved as a unilateral contact problem with friction, following the method developed by Kalker (1982a, b) for the contact problem between two solids. The method employed is fully described in a previous paper and only the main points will be recalled here (Dubourg and Villechaise, 1989).

Each crack is considered as a potential contact area, where $p_{i}$ discretization points are distributed. These points coincide with the collocation points $s_{k}$ (cf. relations 23 or 25). Displacement and stress expressions at a general mesh point are given by Eqs. (14), (15), and (16). The problem requires the solution of $2 \mathrm{NI}$ equalities, $2 \mathrm{NI}$ inequalities for $2 \mathrm{NI}$ unknowns $b_{x}\left(r_{i}\right)$ and $b_{y}\left(r_{i}\right)$, where $\mathrm{NI}$ is defined by $\mathrm{NI}=\sum_{i=1}^{m} p_{i}, m$ being the total number of cracks. Note that the normal and the tangential tractions are coupled. The contact problem is split in two parts, the normal (N) and the tangential (T) problems. In the normal problem the contact and open zone distribution along the crack faces are determined. The stick and slip zone distribution along the potential contact zone is given by the tangential problem. (N) and (T) are solved in turn (N.T/ $\mathrm{N} . \mathrm{T} / . .$. ), until convergence is reached, i.e., when the distribution of stick, slip, and open zones is stabilized from one iteration to the next.

Initial conditions are needed. In the first load step, the cracks are assumed to be closed and adherent (Eqs. (8) and (10), respectively). In a multiple load step problem, the distribution of the different zones obtained in the former pass is used to initiate the next one. Corresponding equations to these initial conditions are then solved for. The solutions are finally tested to see if they satisfy the boundary conditions in terms of the inequalities.

First, the normal problem: $\sigma_{n t}$ is given. Two iteratives procedures are used:

Condition (9) is first verified for all points belonging to the potential contact zone; points which do not verify this con- in the stick zone. A modification introduced in the second iteration implies going over both iterative sequences again.

Global convergence is reached when stable solutions are obtained successively throught $(\mathrm{N})$ and $(\mathrm{T})$. Results give the open, slip and stick zones distribution along crack faces.

This method was successfully applied to the single crack interfacial contact problem. Numerous tests were performed (Dubourg, 1989). They include comparison with:

- The literature for a crack perpendicular to the surface (Hills and Comninou, 1985a, b) and also for an arbitrarily oriented crack (Bower, 1988). Good agreement is obtained in both cases for all contact conditions. The general model presented here is thus as accurate as the specific models to which it was compared.

-Experimental results (Dubourg et al., 1988): differences between the SIFs obtained experimentally using photoelasticity for a cracked PSM4 slab and the theoretical ones do not exceed 15 percent.

For the multiple crack problem, convergence is slowed down because of the increased number of unknowns and of mutual interactions between cracks. But no particular difficulties have been encountered.

A systematic study of the effect of the governing parameters is under way. An application is presented below.

\section{Application Effect of a Moving Load Over the Sur- face of a Multiple Cracked Half-Space}

Here, a moving load of width $L=440 \mu \mathrm{m}$ is applied over the surface of a half-plane which exhibits two cracks. For each

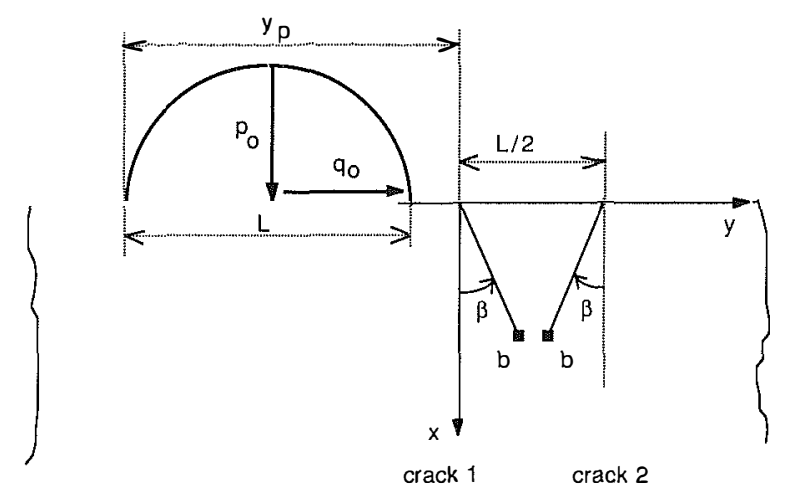

Fig. 2 Moving load over the surface of a two cracked half-plane. po $=840 \mathrm{MPa}$, qo/po $=0.05, \mathrm{~L}=440 \mu \mathrm{m}, b=110 \mu \mathrm{m}, \beta=65 \mathrm{deg}, t=$ 0.1 . 


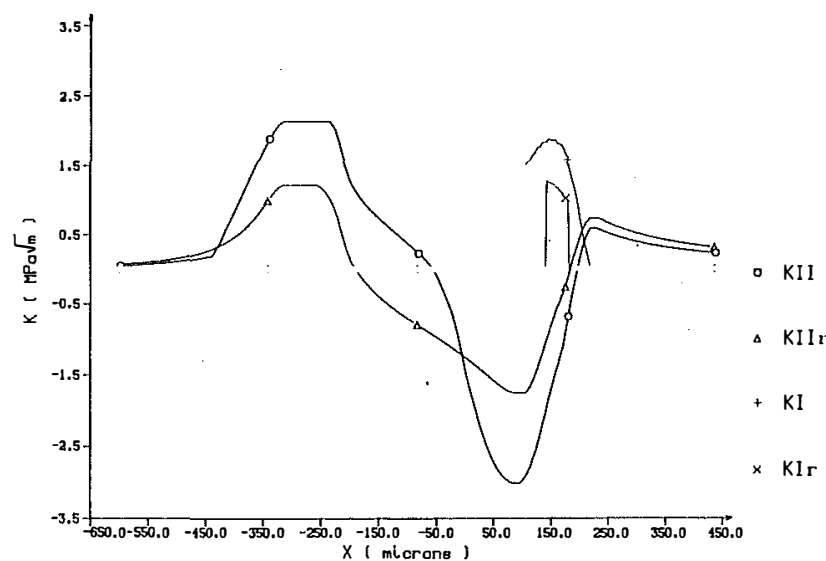

Fig. $3 \mathrm{KI}$ and $\mathrm{KII}$ variations versus $y_{p}$ for the single and two crack configuration. Crack 2

crack, its position $d_{y i}$ dimension $b_{i}$, angle $\beta_{i}$ and interfacial coefficient of friction $f_{i}$ are specified on Fig. 3:

Crack $1 d_{y 1}=0 ., \quad b_{1}=110 \mu \mathrm{m}, \quad \beta_{1}=65^{\circ}, \quad \mathrm{f}_{1}=0.1$ Crack $2 d_{y 2}=220 \mu \mathrm{m}, b_{2}=110 \mu \mathrm{m}, \beta_{2}=-65^{\circ}, f_{2}=0.1$

30 discretization points are considered for each crack. The conditions pictured in that figure are representative of damage found under lubricated Hertzian contacts and have been analyzed for the reference case by Bower (Bower, 1988). The pressure distribution is thus Hertzian, with maximum pressure $p o=840 \mathrm{MPa} ; q o$ is the maximum tangential traction (qo/ $p o=0.05)$. The position of the load is defined with respect to the trailing edge of the loading zone $y_{p} .490$ steps of displacement between $y_{p}=-600 \mu \mathrm{m}$ and $y_{p}=440 \mu \mathrm{m}$ have been analyzed. Comparisons are made between the SIFS obtained when either one (the reference case) or two cracks are present.

Analyses have been performed for the one crack and two cracks systems. Significant interactions between the cracks appear from $y_{p}=-440 \mu \mathrm{m}$, as the leading edge of the loading zone passes over the mouth of crack 1 , to $y_{p}=200 \mu \mathrm{m}$, roughly when the mouth of crack 2 emerges from the loading zone. These interactions are characterized by increases and drops of the SIFs KI and KII compared with those obtained in the reference case KIr and KIIr (Figs. 3 and 4). This would be expected as the presence of a second crack modifies the halfplane rigidity and more particularly the rigidity of the detached zone between the two cracks as it will be shown.

Complex evolutions of the states of the cracks occur as the load moves over the surface (Fig. 5). Note that the displacement zones are pictured proportionally to the other dimensions of the figure (crack length $b$, loading zone $L$ ). Crack states will be seen to be quite complex under some conditions as up to 5 different zones may be found.

As the load starts moving $\left(y_{p}=-600 \mu \mathrm{m}\right)$, the two cracks are partially open; a backward slip zone holds along the faces of crack 1 and a forward slip zone along the faces of crack 2 . Thus the detached zone between the cracks is pulled up. From the start to $y_{p}=-309 \mu \mathrm{m}$, i.e., when the leading edge of the loading zone passes over the tip of crack 2 , the state of crack 2 doesnt' change.

As the leading edge of the load passes over the mouth of crack $1\left(y_{p}=-437 \mu \mathrm{m}\right)$ slip between the faces of crack 1 changes direction. Then the open zone of crack 1 moves gradually from the mouth to the tip: first a closed zone spreads out beneath the mouth, dividing the open zone $\left(y_{p}=-432 \mu \mathrm{m}\right)$ in two zones. Second, a third open zone starts to grow from crack tip $\left(y_{p}=-430 \mu \mathrm{m}\right)$ and finally these two zones connect $\left(y_{p}=-426 \mu \mathrm{m}\right)$. Note that there is still a small contact slip zone beneath the mouth of the crack that prevents the crack from being completely open;

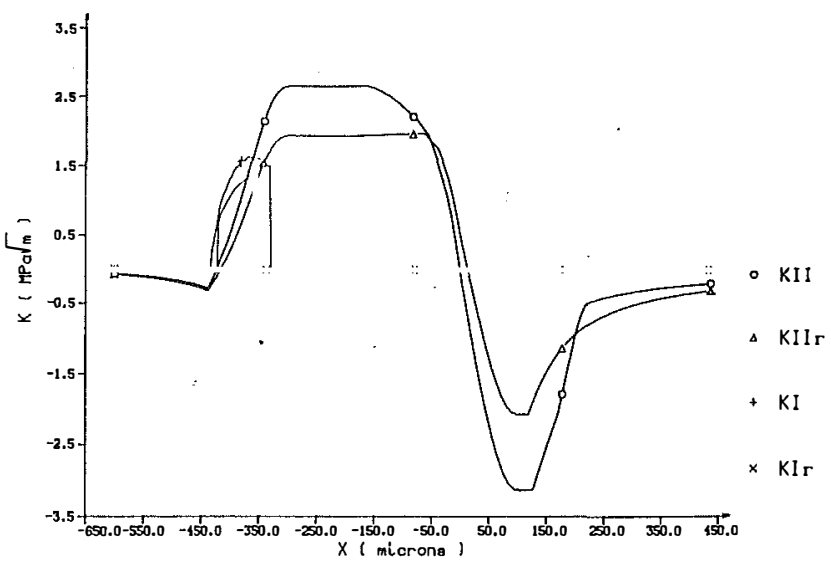

Fig. $4 \mathrm{KI}$ and $\mathrm{KII}$ variations versus $y_{p}$ for the single and two crack configuration. Crack 1

As motion continues, the crack faces reclose gradually because of the compressive action of the loading zone: the forward slip zone progresses toward the tips, a stick zone appears in its middle $\left(y_{p}=-348 \mu \mathrm{m}\right)$ and the open zone disappears $\left(y_{p}=-328 \mu \mathrm{m}\right)$;

Motion continues and the compressive action of the loading zone on both cracks increases. As the leading edge of the loading zone passes over the top of crack $2\left(y_{p}=-309 \mu \mathrm{m}\right) \mathrm{a}$ stick zone starts to grow at the tip of crack 2 . Then, cracks 1 and 2 lock gradually, more specifically, the stick zone of crack 1 progresses toward the tip $\left(y_{p}=--289 \mu \mathrm{m}\right)$, then extends toward the mouth. For crack 2, the stick zone spreads from tip to mouth $\left(y_{p}=-243 \mu \mathrm{m}\right)$. The cracks remain locked until the leading edge of the loading zone approaches the mouth of crack 2 . Here a small backward slip zone appears first at crack 2 tip $\left(y_{p}=-237 \mu \mathrm{m}\right)$ and then spreads along the faces of that crack $\left(y_{p}=--224 \mu \mathrm{m}\right)$. At this point these relative displacements along the faces of crack 2 induce a backward slip zone between the faces of crack $1\left(y_{p}=-163 \mu \mathrm{m}\right)$ (instead of $y_{p}=-50 \mu \mathrm{m}$ for a unique crack) that spreads from tip to the mouth $\left(y_{p}=-55 \mu \mathrm{m}\right)$. As the mouth of crack 1 emerges gradually from the trailing edge of the loading zone, the open zone at its mouth gradually increases and a small stick zone divides a forward slip zone situated under the open zone from the backward slip zone $\left(y_{p}=64 \mu \mathrm{m}\right)$. This forward slip zone extends gradually to the tip of the crack until the backward slip zone and the stick zone disappears $\left(y_{p}=138 \mu \mathrm{m}\right)$. From this load position to the end of the loading cycle, the state of crack 1 remains constant.

A few steps before, two stick zones appear simultaneously at the tip and at the mouth of crack $2\left(y_{p}=86 \mu \mathrm{m}\right)$. Then, a forward slip zone $\left(y_{p}=95 \mu \mathrm{m}\right)$ and an open zone $\left(y_{p}=103\right.$ $\mu \mathrm{m})$ appear one after the other at crack tip. Note that at that time the trailing edge of loading zone is roughly above the tip of crack 2 . As the trailing edge approaches the mouth of crack 2 , the open zone at crack tip increases, the backward slip zone $\left(y_{p}=138 \mu \mathrm{m}\right)$ and the stick zone $\left(y_{p}=173 \mu \mathrm{m}\right)$ are eliminated. There is only one contact slip zone in the middle of the crack. This tendency to open from the tip of the crack then reverses. The open zone is divided in two $\left(y_{p}=201 \mu \mathrm{m}\right)$; the upper one translates along the crack length until it reaches the mouth $\left(y_{p}\right.$ $=216 \mu \mathrm{m})$ and the open zone at crack tip disapears $\left(y_{p}\right.$ $=218 \mu \mathrm{m}$ ) just as the mouth emerges from the trailing edge of the loading zone. There is finally a forward slip zone at crack tip and an open zone at crack mouth. The last change in the crack state concerns the slip direction along the contact zone which reverses. The reversal requires first that a stick zone grows starting from crack tip $\left(y_{p}=222 \mu \mathrm{m}\right)$ then at both end of this zone a backward slip zone appears and spreads out the stick zone $\left(y_{p}=232 \mu \mathrm{m}\right)$. From this point to the end of 


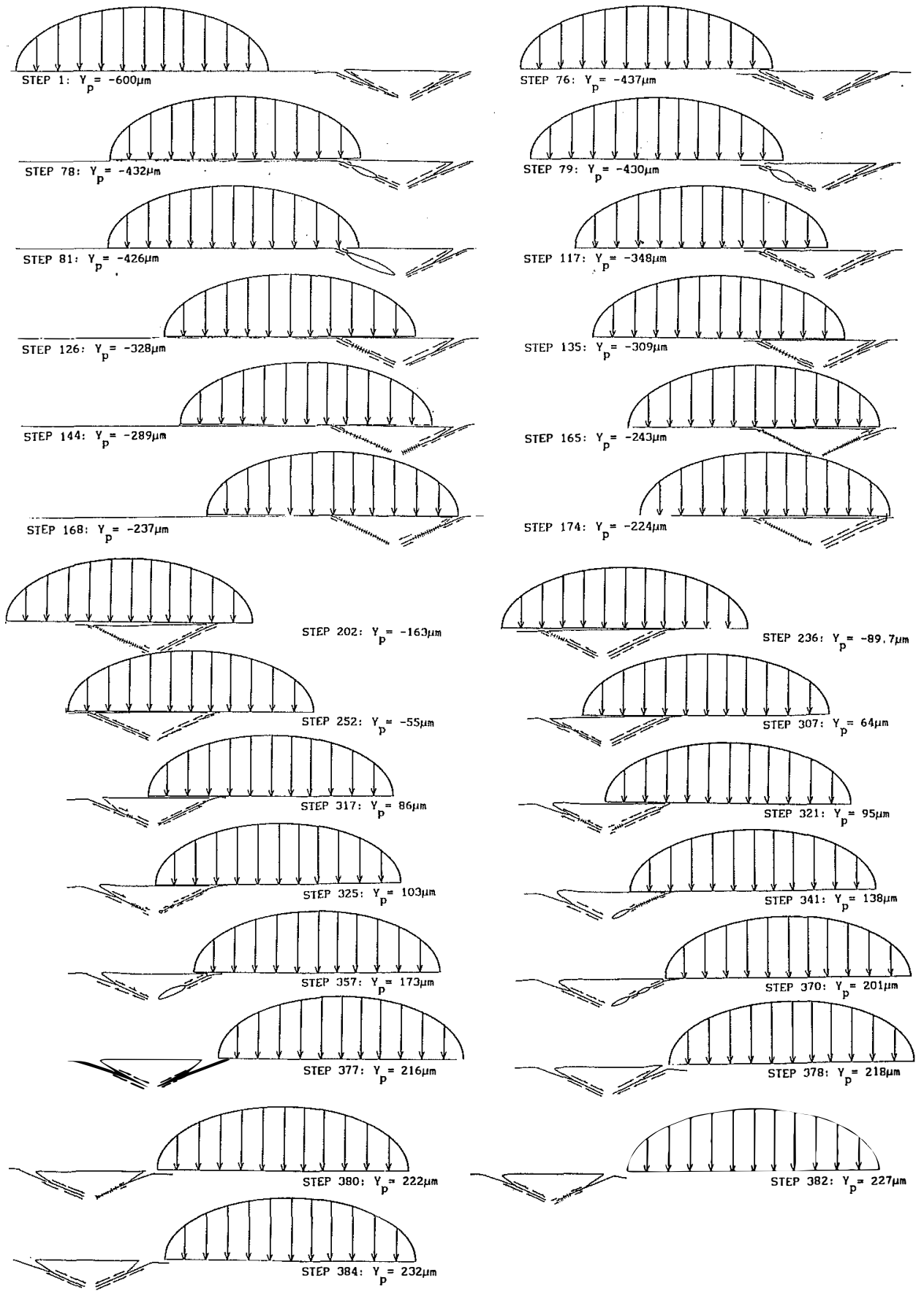

Fig. 5 States of crack 1 and 2 when the load moves over the surface. HHt Stick zone, $\rightleftharpoons$ Forward slip zone, $=$ backward slip zone, > open zone

the loading cycle no more change in the state of crack 2 will occur.

Significant interactions occur at key positions of the loading zone compared with the crack positions:

For crack 1, increases of 32 percent (from $2 \mathrm{MPa} m$ to 2.65 $\mathrm{MPa} \mathrm{m}$ ) and 47 percent (from $-2.1 \mathrm{MPa} \mathrm{m}$ to $-3.1 \mathrm{MPa} \mathrm{m}$ ) are noted. The biggest value is obtained when the trailing edge of the loading zone is situated just between the 2 cracks, and thus above the tips of the cracks.

For crack 2, increases are more important than for crack 1. Increases up to 76 percent (from 1.2 $\mathrm{MPa} \mathrm{m}$ to $2.1 \mathrm{MPa} \mathrm{m}$ ) and 71 percent (from $-1.75 \mathrm{MPa} \mathrm{m}$ to -3 . $\mathrm{MPa} \mathrm{m}$ ) are noted. The biggest interaction occurs from $y_{p}=-440 \mu \mathrm{m}$, as the leading edge of the loading zone is situated over the mouth of crack 1 , to $y_{p}=-328 \mu \mathrm{m}$, as the leading edge passes over the tip of crack 1 . Further crack 1 influences crack 2 significantly over a great distance from $y_{p}=-400 \mu \mathrm{m}$ to $y_{p}=150 \mu \mathrm{m}$. Note that there is a transition zone from $y_{p}=-100 \mu \mathrm{m}$ to $y_{p}=100$ $\mu \mathrm{m}$ : the influence of crack 1 is at first negative (because KII increases) then nearly nil (KII values have opposite sign but the same values), and then the influence is positive (KII decreases). This phenomenon is less marked for crack 1 . These interactions are due to the relative displacements generated along the faces of the other crack that create or amplify displacements along the faces of the first one and vice-versa. For instance, displacements along crack 2 faces induce slip between crack 1 faces from $y_{p}=-163 \mu \mathrm{m}$ instead of $y_{p}=-50 \mu \mathrm{m}$ for the reference case. Note that the detached zone between the two cracks experiences different kinds of movements because of these relative displacements: global displacement up (as for 
$y_{p}=-600 \mu \mathrm{m}$ ) or down (as for $y_{p}=232 \mu \mathrm{m}$ ), a clockwise (as from $y_{p}=-437$ to $-243 \mu \mathrm{m}$ ) or a counterclockwise (as from $y_{p}=-163$ to $\left.-55 \mu \mathrm{m}\right)$ rotation.

Note also that at the end of the loading cycle, SIFs experienced at crack tips 1 and 2 are slightly different compared with the reference values: this is due to the hysteresis induced by friction between crack faces.

\section{Conclusion}

SIFs, elastic fields have been determined for a multiple cracked half-plane. Any loading condition and interfacial contact conditions can be considered owing to the generality of the model. The illustration presented proves that a systematic solution of the contact problem due to the complexity of the states of the cracks during the load cycle is needed. Further, these results show that analysis should not be limited to single cracks only as significant differences in crack states induce important SIFs variations, as much as KII increases of 70 percent.

\section{Acknowledgments}

Part of this work was performed under CEE-Brite contract $\mathrm{N}^{\circ} \mathrm{RI}$ 1B-0249-C (Project $\mathrm{N}^{\circ} 2418$ ). The authors wish to thank the European Community and the industrial partners of the programme, SNECMA and BMW-RR, for the authorization to publish these results.

\section{References}

Bower, A. F., 1988, "The Influence of Crack Face Friction and Trapped Fluid on Surface Initiated Rolling Contact Fatigue Cracks," ASME JournaL of Tribology, Vol. 110, pp. 704-711.

Chang, F. K., Comninou, M., Sheppard, S., and Barber, J. R., 1984, “The Subsurface Crack Under Conditions of Stick and Slip Caused by a Surface Normal Force," ASME Journal of Applied Mechanics, Vol. 51, pp. 311-316.

Comninou, M., 1977, "The Interface Crack," ASME Journal of Applied Mechanics, Vol. 44, pp. 631-636.

Comninou, M., 1978, "The Interface Crack in a Shear Field," ASME Journal of Applied Mechanics, Vol. 45, pp. 287-290.

Comninou, M., and Schmueser, D., 1980, "Frictional Slip Between a Layer and a Substrate Caused by a Normal Load," Int. J. of Engng. Sci., Vol. 18, pp. 131-137.

Comninou, M., Barber, J. R., and Dundurs, J., 1983, “Interface Slip Caused by a Surface Moving at Constant Speed,” Int. J. of Mech. Sci., Vol. 25, No. 1, pp. 41-46.

Dubourg, M. C., Mouwakeh, M., and Villechaise, B., 1988, "Interaction Fissure-Contact-Etude théorique et expérimentale," J. of Theoretical and Applied Mechanics, Vol. 7, No. 5, pp. 623-643.

Dubourg, M. C., Villechaise, B., 1989, “Unilateral Contact Analysis of a Crack With Friction," European J. Mech., A/Solids, Vol. 8, No. 4, pp. 309319.

Dubourg, M. C., 1989, "Le Contact Unilatéral Avec Frottement le Long de Fissures de Fatigue dans les Liasisons Mécaniques," Thèse Doctorat, Institut National des Sciences Appliquées de Lyon, 253 p.

Dundurs, J., and Mura, T., 1964, "Interaction Between an Edge Dislocation and a Circular Inclusion," J. Mech. Phys. Solids, Vol. 12, p. 177-189.

Erdogan, F., Gupta, G. D., and Cook, T. S., 1973, "Numerical Solution of Singular Integral Equations. Method of Analysis and Solutions of Crack Problems; Ed. by G. C. Sih. Leyden, Noordhoff International Publishing, 1973, pp. $368-425$.

Keer, L. M., Bryant, M. D., and Haritos, G. K., 1982, "Subsurface and Surface Cracking Due to Hertzian Contact," ASME Journal of Lubrication TeChNology, Vol. 104, pp. 347-351.

Keer, L. M., and Bryant, M. D., 1983, “A Pitting Model for Rolling Contact Fatigue," ASME Journal of Lubrication TeChNology, Vol. 105, pp. 198205.

Kim, S. H., Keer, L. M., and Cheng, H. S., 1990 "Loss of Adhesion of a Layer Bonded to an Elastic Half-Space Caused by a Concentrated Contact," Tribology Transactions, Vol. 33, No. 1, pp. 53-59.

Krenk, S., 1975, "On The Use of the Interpolation Polynomial for Solutions for Singular Integral Equations," Quart. J. Applied Mech., Vol. 32, pp. 479484

Hills, D A., Comninou, M., 1985a, "A Normally Loaded Half Plane with an Edge Cracks," Int. J. of Solids Structures, Vol. 21, No. 4, pp. 399-410.

Hills, D. A., Comninou, M., 1985b, "An Analysis of Fretting Fatigue Cracks During Loading Phase," Int. J. of Solids Structures, Vol. 21, No. 7, pp. 721730.

Kalker, J. J., 1982a, "Two Algorythms for the Contact Problem in Elasto- statics," Delf, Université de Technologie, 8 pp. Report of the Department of Mathematics and Informatics No. 82-26.

Kalker, J. J., 1982b, "The Contact Between Wheel and Rail," Delft, Université de Technologie, $36 \mathrm{pp}$. Report of the Department of Mathematics and Informatics No. 82-27.

Miller, G. R., and Stock, W. L., 1989, "Analysis of Branched Interface Cracks Between Dissimilar Anisotropic Media," ASME Journal of Applied Mechanics, Vol. 56, pp. 844-849.

Nowell, D., and Hills, D. A., 1987, "Open Cracks at or Near Free Edges," Journal of Strain Analysis, Vol. 22.

Sheppard, S. D., Hills, D. A., and Barber, J. R., 1986, "An Analysis of Fretting Cracks. Part 2: Unloading and Reloading Phases," Int. J. of Solids Structures, Vol. 23, pp. 140-152.

\section{A P P E N D I X}

The $K_{i j}^{x}, K_{i j}^{x}$ kernels expressions are:

$$
\begin{gathered}
K_{n n}^{x}=K_{x x}^{x} \sin ^{2} \beta-2 K_{x y}^{x} \sin \beta \cos \beta+K_{y y}^{x} \cos ^{2} \beta \\
K_{t t}^{x}=K_{x x}^{x} \cos ^{2} \beta-2 K_{x y}^{x} \cos \beta \sin \beta+K_{y y}^{x} \sin ^{2} \beta \\
K_{n t}^{x}=\left(K_{y y}^{x}-K_{x x}^{x}\right) \sin \beta \cos \beta+K_{x y}^{x}\left(\cos ^{2} \beta-\sin ^{2} \beta\right)
\end{gathered}
$$

$K_{n n}^{t}, K_{n t}^{y}$ and $K_{t t}^{y}$ are defined in the same way with $K_{x x}^{y}, K_{x y}^{y}$, $K_{y y}^{y}$. For a point $M(x, y)$ situated in a general position along the crack, for a dislocation $S(\xi, \eta)$ of Burgers vectors $b_{x}, b_{y}$, elementary stress and displacements are expressed in the reference axis $\left(x_{\eta}, y_{\eta}\right)$ such as $x_{\eta}=x, y_{\eta}=y-\eta$ (Fig. 1). Thus the $K_{1 m}^{x}, K_{1 m}^{y}$ kernels expressions where the subscripts $1, m=x, y$ are identical to those obtained for a crack perpendicular to the surface:

$$
\begin{aligned}
& k_{x y}^{x}\left(x, y_{\eta}, \xi\right)=\left(\frac{x_{1}}{r_{1}{ }^{2}}-\frac{x_{2}}{r_{2}{ }^{2}}\right)-2 y^{2}\left(\frac{x_{1}}{r_{1}{ }^{4}}-\frac{x_{2}}{r_{2}{ }^{4}}\right) \\
&+2 \xi\left(\frac{1}{r_{2}{ }^{2}}-\frac{2 y^{2}}{r_{2}{ }^{4}}\right)+2 \xi x\left(-\frac{2 x_{2}}{r_{2}{ }^{4}}+\frac{8 y^{2} x_{2}}{r_{2}{ }^{6}}\right) \\
& k_{x x}^{x}\left(x, y_{\eta}, \xi\right)=y\left\{-3\left(\frac{1}{r_{1}{ }^{2}}-\frac{1}{r_{2}{ }^{2}}\right)+2 y^{2}\left(\frac{1}{r_{1}{ }^{4}}-\frac{1}{r_{2}{ }^{4}}\right)\right. \\
&\left.-\frac{4 x \xi}{r_{2}{ }^{4}}\left(-3+\frac{4 y^{2}}{r_{2}{ }^{2}}\right)\right\}
\end{aligned}
$$

$k_{y y}^{x}\left(x, y_{\eta}, \xi\right)=y\left\{-\left(\frac{1}{r_{1}^{2}}+\frac{1}{r_{2}^{2}}-\frac{2 x_{1}^{2}}{r_{1}{ }^{4}}+\frac{2 x_{2}^{2}}{r_{2}{ }^{4}}\right)\right.$

$$
\left.+\frac{4 \xi}{r_{2}^{4}}\left(3 x+2 \xi-4 x \frac{x_{2}^{2}}{r_{2}^{2}}\right)\right\}
$$

$k_{y y}^{y}\left(x, y_{\eta}, \xi\right)=\left(\frac{x_{1}}{r_{1}^{2}}-\frac{x_{2}}{r_{2}^{2}}\right)+2 y^{2}\left(\frac{x_{1}}{r_{1}^{4}}-\frac{x_{2}}{r_{2}^{4}}\right)$

$$
+2 \xi\left[-\frac{1}{r_{2}{ }^{2}}+\frac{8 x x_{2}^{2} y}{r_{2}{ }^{6}}+\frac{2 \xi x_{2}}{r_{2}^{4}}\right]
$$

$k_{x x}^{y}\left(x, y_{\eta}, \xi\right)=\left(\frac{x_{1}}{r_{1}^{2}}-\frac{x_{2}}{r_{2}^{2}}\right)-2 y^{2}\left(\frac{x_{1}}{r_{1}^{4}}-\frac{x_{2}}{r_{2}^{4}}\right)$

$$
\left.+2 \xi\left[-\frac{1}{r_{2}{ }^{2}}-\frac{4 x_{2}^{2}}{r_{2}{ }^{4}}+\frac{8 x x_{2}^{3}}{r_{2}{ }^{6}}+\frac{6 \xi x_{2}}{r_{2}{ }^{4}}\right]\right\}
$$

$k_{x y}^{y}\left(x, y_{\eta}, \xi\right)=y\left\{\left(\frac{1}{r_{1}{ }^{2}}-\frac{1}{r_{2}{ }^{2}}\right)-2 y^{2}\left(\frac{1}{r_{1}{ }^{4}}-\frac{1}{r_{2}^{4}}\right)\right.$

$$
\left.+4 x \xi\left(\frac{4 x_{2}^{2}}{r_{2}^{6}}-\frac{1}{r_{2}^{4}}\right)\right\}
$$

$u_{x}(x, y)=\frac{1}{2 \pi(k+1)}\left[D_{x}^{x}\left(x, y_{\eta}, \theta, \xi\right) . b x(\xi)+D_{x}^{y}\left(x, y_{\eta}, \theta, \xi\right) . b y(\xi)\right]$

$u_{y}(x, y)=\frac{1}{2 \pi(k+1)}\left[D_{y}^{x}\left(x, y_{\eta}, \theta, \xi\right) . b x(\xi)+D_{y}^{y}\left(x, y_{\eta}, \theta, \xi\right)\right.$. by $\left.(\xi)\right]$

$D_{x}^{x}\left(x, y_{\eta}, \theta, \xi\right)=\left[(k+1)\left(\theta_{1}-\theta_{2}\right)+2 y_{\eta}\left(\frac{x_{1}}{r_{1}^{2}}-\frac{x_{2}}{r_{2}^{2}}\right)\right.$ 


$$
\begin{array}{ll}
\left.-2 \xi\left[(k-1) \frac{y_{\eta}}{r_{2}^{2}}+\frac{4 x_{2}^{2}}{r_{2}^{4}} y_{\eta}-4 \xi \frac{x_{2} y_{\eta}}{r_{2}^{4}}\right]\right] & +2 \xi\left((1-k) \frac{x_{2}}{r_{2}^{2}}-\frac{4 x_{2}^{3}}{r_{2}^{4}}+2 \xi\left(\frac{-1}{r_{2}^{2}}+\frac{2 x_{2}^{2}}{r_{2}^{4}}\right)\right) \\
\left.\log r_{2}-\log r_{1}\right)+2\left(\frac{x_{2}^{2}}{r_{2}^{2}}-\frac{x_{1}^{2}}{r_{1}^{2}}\right) & D_{y}^{y}\left(x, y_{\eta}, \theta, \xi\right)=(k+1)\left(\theta_{1}-\theta_{2}\right)-2 y_{\eta}\left(\frac{x_{1}}{r_{1}^{2}}-\frac{x_{2}}{r_{2}^{2}}\right)
\end{array}
$$

$$
\begin{aligned}
D_{y}^{x}\left(x, y_{\eta}, \theta, \xi\right)=(k-1)( & \left(\log r_{2}-\log r_{1}\right)+2\left(\frac{x_{2}{ }^{2}}{r_{2}^{2}}-\frac{x_{1}{ }^{2}}{r_{1}^{2}}\right) \\
-2 \xi & {\left[(3+k) \frac{x_{2}}{r_{2}^{2}}-\frac{4 x_{2}^{3}}{r_{2}^{4}}-2 \xi\left(\frac{1}{r_{2}^{2}}-\frac{2 x_{2}^{2}}{r_{2}^{4}}\right)\right] }
\end{aligned}
$$$$
+2 \xi\left((k-1) \frac{y_{\eta}}{r_{2}^{2}}-4 \frac{x_{2}^{2}}{r_{2}^{4}} y_{\eta}+\frac{4 \xi x_{2} y_{\eta}}{r_{2}^{4}}\right)
$$

$D_{x}^{y}\left(x, y_{\eta}, \theta, \xi\right)=(k-1)\left(\log r_{1}-\log r_{2}\right)-2\left(\frac{x_{1}^{2}}{r_{1}^{2}}-\frac{x_{2}^{2}}{r_{2}^{2}}\right)$

where

$x_{1}=x-\xi, x_{2}=x+\xi, r_{1}^{2}=x_{1}^{2}+y_{\eta}^{2}, r_{2}^{2}=x_{2}^{2}+y_{\eta}^{2}$. 